Archives de sciences sociales des religions

148 | octobre-décembre 2009

Bulletin Bibliographique

\title{
Sonia Sarah LIPSYC, (dir.), Femmes et judaïsme aujourd'hui
}

Paris, Éditions In Press, 2008, 350 p.

Daniel Vidal

\section{CpenEdition}

Journals

Édition électronique

URL : http://journals.openedition.org/assr/21160

DOI : $10.4000 /$ assr.21160

ISSN : 1777-5825

Éditeur

Éditions de l'EHESS

Édition imprimée

Date de publication : 31 décembre 2009

Pagination : $75-342$

ISBN : 978-2-7132-2218-4

ISSN : 0335-5985

Référence électronique

Daniel Vidal, «Sonia Sarah LIPsyc, (dir.), Femmes et judaïsme aujourd'hui », Archives de sciences sociales des religions [En ligne], 148 | octobre-décembre 2009, document 148-84, mis en ligne le 03 juin 2009, consulté le 21 septembre 2020. URL : http://journals.openedition.org/assr/21160 ; DOI : https:// doi.org/10.4000/assr.21160

Ce document a été généré automatiquement le 21 septembre 2020.

(C) Archives de sciences sociales des religions 


\title{
Sonia Sarah LIPSYC, (dir.), Femmes et judaïsme aujourd'hui
}

Paris, Éditions In Press, 2008, 350 p.

\author{
Daniel Vidal
}

\section{RÉFÉRENCE}

Sonia Sarah LIPSYc, (dir.), Femmes et judaïsme aujourd'hui, Paris, Éditions In Press, $2008,350 \mathrm{p}$.

1 En mars 2004, trois journées de réflexions sur le thème « Femmes et Judaïsme dans la société contemporaine» se sont tenues au Musée d'Art et d'Histoire du Judaïsme. L'ouvrage dirigé par Sonia S. Lipsyc en est l'aboutissement. Si le regroupement des interventions s'opère à partir de la question du statut actuel de la femme en judaïsme, et veut s'inscrire dans la vaste constellation des gender studies, la plupart d'entre elles, et c'est leur originalité, tendent à dépasser ce cadre un peu convenu, et forcément hétérogène, pour faire retour incisif et lucide sur les arguments qui, dans l'histoire plurimillénaire du judaïsme, ont fixé, parfois modifié à la marge, ce statut et son inscription dans les catégories fondamentales de la religion juive. Il est ainsi rappelé avec force que la question de la femme, et, plus largement et rigoureusement, du féminin, constitue le point névralgique, incontournable et explosif - fût-il objet de dénégation, ainsi qu'il en va en toute religion -, autour duquel, et contre lequel, le judaïsme s'est constitué. Du moins en son versant traditionnel ou orthodoxe, qui demeure le référentiel le plus sollicité par les agents de l'institution. Il apparaît alors que la situation aujourd'hui de la femme en judaïsme ne peut se comprendre, et se contester, que par l'examen des sources scripturaires - Torah écrite (Pentateuque) et orale, Talmud (transcription de celle-ci), et ses interprétations cumulées et commentées (Michna et Guemara). En ces sources longuement déchiffrées et diffusées, s'est décidé un statut de la femme qui l'écarte de toute lecture, et a fortiori de tout enseignement, du Talmud, c'est-à-dire de ce qui constitue, selon l'expression de Sarah 
Lipsyc, « la clé de voûte de la loi juive ». Ainsi les femmes sont-elles « soumises à une loi sans y avoir été initiées ». Tout converge en judaïsme traditionnel vers cet interdit fait à la femme d'accéder à l'espace du sacré, dont il lui est cependant réclamé d'observer les préceptes et les rituels. Tout, depuis le système juridique (" halakhique ») jusqu'aux récits et paraboles régissant la vie quotidienne (aggada, midrach). Comme il en va souvent en matière de loi, la source en peut être, selon S. Lipsyc, une interprétation tendancieuse du terme définissant le récepteur de la Torah: «ben», fils (au sens restreint), ou enfant (au sens plus général, donc fils/fille). Privilégier la première acception est faire un choix déterminant dans l'économie de la Loi, dont seuls les hommes seraient les destinataires légitimes. De l'Antiquité (rabbi Eliezer, $\mathrm{III}^{\mathrm{e}}$ siècle) au Moyen Âge (Maïmonide), théologiens, rabbins et philosophes vont ainsi justifier l'interdit qui rejette la femme dans la seule observance d'une loi dont elle n'a, à vrai dire, ni science ni connaissance. "Plutôt brûler les paroles de la Torah que de les confier aux femmes ». Initier les femmes à l'étude de la loi « est au mieux inutile, au pire provoquerait des désastres ", résume l'auteure, car la femme, privée de conducteur avisé et vigilant, n'y lirait que «bavardage » ou "insanités ». Mais ce qui se joue, en cette disjonction radicale de la loi et de la femme, c'est le maintien d'un ordre hiérarchique dont la première place revient «naturellement » à l'homme - et le travail de tricotage/détricotage des textes n'a que ce seul but: faire dire aux mots la prééminence du masculin.

2 Longtemps la femme juive fut donc exclue de la lecture de la Loi, et ne put occuper, dans la synagogue, qu'une place à l'écart, galerie séparée, ou rideau cachant l'office, sans jamais accéder aux fonctions sacerdotales. Longtemps ? Jusqu'à la fin du $\mathrm{xx}^{\mathrm{e}}$ siècle, qui lèvera les interdits. Mais la "lutte" pour cette véritable émancipation, dont on trouve plus d'un témoignage dans l'histoire religieuse du peuple d'Israël, toujours minoritaires et sans effets à long terme, commença réellement avec l'apparition du courant rationaliste et la figure et l'action de Hafetz Hayyim (1838-1933), qui demandait que l'on transgressât l'une des lois fondamentales de la Loi juive, afin que fût sauvé le judaïsme en tant que tel. Ainsi de la possibilité pour les femmes de lire la Torah, et de participer de pleine légitimité à la conduite de l'appareil religieux. Il devenait en effet insupportable de maintenir cet interdit, dès lors que l'on continuait à réserver aux femmes la transmission de la judéité. Danielle Storper-Perez analyse ce paradoxe, qui apparente "mémoire » et "masculin », de même racine linguistique - et réserve aux femmes l' «accueil d'un sens donné par la loi ». À l'homme, le pouvoir parce que l'étude; à la femme, la gestion de la vie quotidienne, parce que l'écoute. Corps religieux-public masculin vs corps religieux-privé féminin. Contre cette stricte répartition des "rôles sociaux et symboliques", vont s'élever les multiples mouvements féministes juifs aux États-Unis (où seront tolérées les écoles des femmes), plus récemment en Israël, et un révisionnisme biblique sans concession. Il ne s'agit pas, dira Judith Plaskow dans les années 1970-1990, de lire la Torah : il faut la réécrire, la recréer, reformuler chaque aspect de la tradition. Non seulement en réhabilitant le rôle des femmes dans l'histoire du judaïsme (Sarah, Esther, Déborah, Myriam, etc.), mais en se «réappropriant» la figure "maléfique » de Lilith. Retournement radical : de cette "première femme d'Adam créée égale à lui ", qui, prononçant «le Nom secret de Dieu ", se condamna à une existence "solitaire et errante ", la Tradition en fit le foyer du diabolique, en sa perversion sexuelle, quand cependant le Zohar la dit « consolatrice de Dieu en l'absence de la présence divine. Sa partie féminine en exil de Lui-Même ». Revisiter cette figure damnée, est à coup sûr en bouleverser la symbolique, en 
l'affectant d'un coefficient de féminité libératrice, qui déconstruit l'interprétation classique et rappelle que le " genre » est construction sociale, sans statut ontologique.

3 Ne procédant pas à la lecture publique de la Torah, n'étant pas associées à l'office public des prières, les femmes sont absentes des fonctions religieuses, et «passent totalement inaperçues dans les synagogues » : Liliane Vana rappelle cet autre paradoxe, qui écarte les femmes de ces fonctions, déduites pourtant... " de la prière de Hannah », mère de Samuel. Les textes anciens avèrent la présence des femmes dans le culte synagogal, et, en état d' "impureté rituelle », leur droit de lire la Torah et de toucher les objets sacrés. Tous ces textes furent cependant soumis à des lectures strictement négatives, afin de ne pas mettre en évidence, en cas d'illettrisme, l'infériorité de l'homme par rapport à la femme cultivée. Mieux vaudrait, dira-t-on depuis l'époque de la Mishna, " annuler la lecture publique de la Torah, que d'en appeler aux femmes ». Le verrou saute, en ces dernières décennies, mais les groupes féminins de prières, s'ils sont tolérés, sont minimisés, et considérés sans pouvoir légal. On peut bien alors, à la suite de Marc Kujawski, tenter d'éclairer positivement ces paroles de la prière obligatoire du matin: "Bénis sois-Tu Éternel Roi du monde qui ne m'a point fait femme ", car l'Adam androgyne ne tient sa masculinité que par l'effacement de sa féminité, alors qu'Ève est d'emblée, avant même de "naître », et la première, nommée femme, et "mère de toutes les créatures ». L'homme n'eut pu véritablement "être ", s'il était né femme... Subtilité féconde, sans doute. Il n'empêche : les paroles demeurent, si les écrits s'envolent. À moins qu'ils ne s'enroulent autour de leur contradiction constitutive. Lire la Genèse, c'est se confronter à cette dualité originelle («mâle et femelle créés à la fois»), et à la création seconde de la femme, réduite ainsi à une « fonction auxiliaire ». Sans doute, note Rivon Krygier, la mixité première doit faire loi : homme et femme forment concert d'égalité. Mais la plupart des rabbins se rallient à l'apostrophe de Rabbi Benaa (III siècle) : « Ève est au regard d'Adam comme le singe au regard de l'humain». Question cruciale: à vouloir maintenir «l'équivalence des puissances " ne risque-t-on pas de vivre en un état permanent d'affrontement? L'ordonnancement hiérarchique du pouvoir éviterait ce risque mortel. Et, on le sait, le pouvoir, c'est l'homme... Peut-on résorber l'asymétrie entre les sexes? Une nouvelle éthique s'imposerait. Mais d'où, cette éthique? D'un miracle au féminin, ainsi qu'en témoignent certains écrits de l'époque talmudique? Oui, si l'on tient pour miracle la dévolution aux femmes de règles culturelles en principes réservées aux hommes, et qui prendraient statuts de devoirs. Ainsi serait établi un nouvel ordre égalitaire.

4 Égalité ne veut pas dire homogénéisation culturelle, mais maintenance de la double polarité, qu'analyse Arouna Lipschitz, entre principe masculin et principe féminin. $\mathrm{Ce}$ qui, au-delà des textes et des paroles théologiennes, et sur le plan ontologique, «revient à assumer la responsabilité d'un double accomplissement de soi ». Deux conséquences en découlent. L'une concerne la relation privilégiée de l'homme au Texte : devoir à proprement parler de mémoire, qui l'inscrit dans une filiation cultuelle et culturelle - je suis «fils de». L'oublierait-il, note A. Lipschitz, tel homme serait "déplacé ». Mais remonter, de texte en texte, de compilation en commentaire, à l'origine, à «Dieu », implique que cette origine demeure de l'ordre de la question, et non du dogme. On sait par ailleurs, que les ensembles textuels de référence, forment autant de chantiers interprétatifs multiples et contradictoires. Chaque "verset » est lieu de chiffrages singuliers. Mais «au-delà du verset»? se demande l'auteur : "Quid des blancs du texte, du silence entre les lignes ? Du sans nom, du hors-texte ? De ce trou sans fond que constitue le mystère de l'absolu...? ». C'est précisément en ce «non lieu » 
que prend pleinement place la parole de femme : elle serait alors " parole au féminin qui touche au vide", c'est-à-dire, ici-même, au lieu d'ignition du sacré, en une approche à la fois «mystique » et « charnelle » du texte. Lecture d'homme et lecture de femme, sont ainsi impensables en leur disjonction. Seules leur combinaison, leur interpénétration, sont sources de signifiance. L'autre conséquence concerne chaque acteur en tant que tel, bien au-delà de sa fonction sacerdotale ou interprétative. C'est le statut "ontologique » de l'être humain qui est alors posé. Si la parole au masculin s'ouvre à la parole au féminin, alors le féminin en l'homme s'avère, et le masculin en la femme, chacun « en accomplissant, dans les deux cas, le féminin et le masculin de son âme ".

5 Ce qui peut aujourd'hui se dire en toute clarté, longtemps fut dénié. Des exégèses raffinées tentèrent en vain de déstabiliser les certitudes doctrinales sur lesquelles se fondait la somme d'interdits dont la femme était l'objet. Ariel Sion présente également quelques figures emblématiques de femmes qui s'inscrivirent cependant dans le judaïsme comme question, mais sans réponse. Sore Bas Tovim, au XVII , figure " mythique ", femme cultivée, écrivaine yiddish, épouse de rabbin ; Glueckel d'Hamelin, fin $\mathrm{XVII}^{\mathrm{e}} /$ début $\mathrm{XVIII}^{\mathrm{e}}$ siècle, dévote et pleinement de son siècle de mille terreurs; Sarah Schenirer (1883-1935), "archétype du militantisme féminin de l'orthodoxie juive ", créatrice de mouvement éducatif, fondatrice d'écoles féminines de lecture religieuse. Cas particuliers de femmes intervenant dans la sphère publique, hors de leur confinement dans le seul espace du foyer familial. Aujourd'hui, cette intervention est la règle, non l'exception. Régine Azria en propose une analyse à double sens. Certes, en judaïsme, les femmes occupent désormais, dans l'institution et dans la société, des fonctions éminentes, et nul savoir, nulle compétence, ne leur sont déniés. Leur promotion professionnelle est reconnue de tous. Un effet pervers, cependant : plus les secteurs d'activité sont féminisés - éducation, santé, recherche, etc. -, plus ils tendent à être dévalués. Ceci vaut pour l'ensemble des femmes en nos sociétés. Mais pour les femmes juives, cet engagement peut conduire à une «marginalisation du savoir traditionnel ", c'est-à-dire du fond même de la culture juive. La génération qui vient sera celle des " enfants rebelles à la modernité », tentant de récupérer des repères en voie d'effacement, et vivant cette modernité comme «forme moderne de l'aliénation féminine ». Processus que renforcent encore les mariages « mixtes », juif ou juive/goy, qu'étudie Joëlle Allouche-Benayoun. Leur augmentation massive pose le problème de la transmission du patrimoine religieux, de la mémoire collective, de l'histoire et de ses naufrages. Il apparaît en effet que si seule la mère est juive, une tendance s'amorce vers une laïcisation globale de la famille et de ses comportements. Si seul est juif le père, la transmission culturelle qui relevait de la mère, lui est dévolue, paradoxalement puisque n'est reconnu juif que l'enfant issu de mère juive. Tel est pourtant le prix à payer pour que perdure la judéité. Faisons un rêve. Se pourrait-il qu'un jour, toute féminité faisant surrection au centre du judaïsme - mais de l'islam aussi bien, et du christianisme - telle femme enfin reconnue comme sujet primordial, inversant la formule qui la niait, s'écrie «Béni sois-tu, seigneur, qui ne m'as point fait homme »? 